\title{
Metalanguage or bidialectism? Acquisition of clitic placement by Hellenic Greeks, Greek Cypriots and binationals in the diglossic context of Cyprus
}

Evelina Leivada, Paraskevi Mavroudi, Anna Epistithiou

Department of English Studies, University of Cyprus, Cyprus

https://doi.org/10.36505/ExLing-2010/03/0025/000145

\begin{abstract}
Acquisition of object clitics is one of the more investigated aspects of the largely understudied variety of Modern Greek spoken in the Republic of Cyprus. Previous studies on the acquisition of clitics in Cypriot Greek usually acknowledge that the linguistic reality in Cyprus involves a state of diglossia, where the sociolinguistically 'high' Standard Modern Greek co-exists with the 'low' Cypriot Greek. Acquisition of clitic placement in simple declaratives is here approached through a picture-based elicitation task by testing both varieties in three populations residing in Cyprus Greek Cypriots, Hellenic Greeks, and binationals — so as to examine implications for bidialectism and its connections with enhanced metalinguistic abilities.
\end{abstract}

Key words: acquisition, clitic placement, Cypriot Greek, diglossia, metalanguage.

\section{Acquisition of clitics in Cypriot Greek}

The sociolinguistic status of the Republic of Cyprus has been linked to trilingualism, bilingualism, or bidialectism (very much depending on the study and the perspective behind it). What is unequivocally admitted is the status of diglossia (Ferguson 1959), and numerous studies have discussed the diglossic status of Cyprus and sociolinguistic aspects of the 'high' variety Standard Modern Greek (SMG) and the 'low' variety Cypriot Greek (CG) as well as the relationship between them (e.g., Papapavlou and Pavlou 1998).

From formal and developmental perspectives, clitics in CG constitute one of the domains that has enjoyed comparatively rich research. Petinou and Terzi (2002) published findings of a longitudinal study to argue that children at age 3 have mastered general clitic production and placement. A more recent pilot study (Grohmann, to appear) reports on a picture-based elicitation task that investigated the acquisition of object clitics in monolingual Greek Cypriot children, between 3 and 6 years of age, which supports the claim that acquisition of object clitics occurs by age 3 in simple declaratives (i.e. indicative environment). In the same study, adults' performance shows $100 \%$ enclitic production; this would reasonably lead to an assumption of adult CG being exclusively enclitic in indicative environments.

Initial results reported by Grohmann et al. (2010), which lay the basis for the presentation in Grohmann (to appear), seem to confirm this assessment.

ExLing 2010: Proceedings of 3rd Tutorial and Research Workshop on Experimental Linguistics, 25-27 August, Athens, Greece 
They extended the groups of CG-speaking children from 3-4- and 5-year-old children to differentiated groups of equal size for 3-, 4-, 5-, and 6-year-olds respectively (around 20 children per age group, but over twice as many 5year-olds), as well as a language-impaired group. We will extend the tested groups further and thereby contribute to the study of clitic placement in young speakers by adding another dimension.

\section{The Study}

The present experiment readdresses the issue of the acquisition of object clitic placement, yet it does so by approaching it from the other aspect of diglossia in Cyprus, that is, by examining the placement of object clitics in children native in the 'high' variety (SMG). These are subsequently referred to as Hellenic Greek children residing in Cyprus (but born and, for a certain period, schooled in Greece, with both parents from Greece) and what we call 'binational' children (born in Greece or Cyprus, with one parent from each country). We employed a picture-based elicitation task (from COST Action A33; Varlokosta et al., to appear) in which children had to complete 12 target sentences inside a because-clause by producing a verb and a clitic.

The experiment consisted of two parts: (i) an SMG-version, slightly differing from the version of COST Action A33 carried out in Greece, and (ii) the CG-version used by Grohmann et al. (2010). The correct answer was provided, if necessary, only in the 2 warm-up stories. Three groups participated in the present study: (i) 40 monolingual Hellenic Greek children, divided into 4 sub-groups (10 in each of the following age groups: $3 ; 0-4 ; 5$, $4 ; 6-5 ; 11,6 ; 0-7 ; 5$, and 7;6-8;11), (ii) 30 binational children (one age group, $3 ; 5-9 ; 1$, mean age 6;5), and (iii) 40 Greek Cypriot children, divided into 4 sub-groups (10 in each age group: $3 ; 0-4 ; 5,4 ; 6-5 ; 11,6 ; 0-7 ; 5$, and 7;6-8;11).

All children were tested twice, once in each (but first in their native) variety, by two different investigators, one SMG-, the other CG-native, and a 7 -day period was allowed between the two sessions. The control groups were 6 Hellenic Greek adults and 6 Greek Cypriot adults, also tested twice. Children were recruited randomly from 36 primary and pre-primary schools in the Nicosia district and tested in the school environment.

\section{Findings}

Children aged 3;0-4;5 produced at least 7 out of 12 clitics in our experiment, a finding that agrees with Petinou and Terzi (2002) and Grohmann et al. (2010) regarding age of acquisition. In the CG-version, Hellenic Greek children ignored the enclisis feedback that the investigator provided them with in the two warm-up stories and did not code-switch. The Hellenic Greek adults had lived in Cyprus for 2 to 6 years, yet they code-switched, if at all, for only the first few test structures, just to show their ability to produce enclisis (as admitted verbally to the experimenter)), but then 
returned to SMG and their proclitic productions. In the SMG-version, all Hellenic Greek adults produced 12 out of 12 pre-verbal clitics. Hellenic Greek children produced very high percentages of proclisis in both versions of the tests. Greek Cypriot adults were different from Hellenic Greeks in significantly producing proclisis (i.e. non-target placement) even when taking the CG-version of the test. Moreover, they performed proclisis (i.e. target placement) when addressing the Hellenic Greek experimenter in the SMG-version of the test to such a great extent that their productions gave rise to a paradox: Their target placement was higher in SMG (98.6\%) than in their native CG (76.6\%). The binational children behaved like the monolingual Hellenic Greek adults, especially in terms of placement, although the vast majority (25/30) was born in Cyprus and certainly schooled for some time, if not entirely, in Cyprus.

Based on the reports of previous acquisition studies, it was initially expected that target placement is proclisis in SMG and enclisis in CG indicative declaratives. However, adult target placement is not $100 \%$ enclitic according to the productions that our task elicited: $76.6 \%$ in the CG version of the test. It should be clarified that all adult Greek Cypriots were tested in the house of one of the experimenters and they also had a certain degree of familiarity with the experimenter, so there is nothing that should make us expect the use of SMG. A look at their production in the fillers that involved productions outside the V-CL/CL-V pattern that our task aimed to elicit shows both the use of inflectional morphology and lexical items that are CGspecific. Based on these data, we suggest that there is no evidence that our adult Greek Cypriots code-switched in SMG, hence proclisis cannot be considered the result of code-switching.

The fact that some Greek Cypriot children who performed 100\% nontarget placement in the CG version commented on their performance or on the experiment's pictures in CG suggests that in bilingual/bidialectal populations especially, children are metalinguistically aware. If Crain and Fodor (1987) are right in suggesting that metalanguage is innate as a medium of representation used to encode observations about language, the link between enhanced metalinguistic abilities and multilingualism established by Bialystock (1991) becomes relevant also for diglossic environments like the one in Cyprus (see Ibrahim et al. 2007 for Arabic). The question raised here is whether the performance of Greek Cypriot children is an instance of code-mixing, as a result of bidialectism, or a(n) (un)conscious demonstration of metalinguistic awareness driven by linguistic anxiety to (show that they are able to) speak 'properly'. Some Greek Cypriot children, even at age 5;10, while trying to align themselves with the 'high' variety, employed non-target placement combined with verbs that do not exist in either variety. By misapplying SMG morphological suffixes to the CG verbal stem, they produced forms that prima facie 
resemble SMG, but are not SMG. Such forms were totally absent from the production of our true bidialectals, that is, the group of binational children, the overwhelming majority of whom used correct SMG, not due to absence of metalinguistic awareness but due to native(-like) SMG performance that disallowed such errors.

\section{Acknowledgements}

At all stages of this experiment, we have received valuable comments by all members of the Cyprus Acquisition Team (CAT), to whom we are grateful. We especially wish to thank Kleanthes Grohmann for co-ordinating, supervising, and (endlessly) supporting our work. All faults remain our own.

\section{References}

Bialystock, E. 1991. Metalinguistic dimensions of bilingual language proficiency. In Bialystock, E. (ed.), Language Processing in Bilingual Children. CUP.

Crain, S., Fodor, J.D. 1987. Simplicity and generality of rules in language acquisition. In MacWhinney, B. (ed.), Mechanisms of Language Acquisition. Hillsdale, NJ: Lawrence Erlbaum.

Grohmann, K.K. To appear. Some directions for the systematic investigation of the acquisition of Cypriot Greek. In Rinke E., Kupisch T. (eds.), The Development of Grammar: Language Acquisition and Diachronic Change - Volume in Honor of Jürgen M. Meisel. Amsterdam: John Benjamins.

Grohmann, K.K., Theodorou, E., Pavlou, N., Leivada, E. 2010. Object clitics in typically-developing and language-impaired Cypriot Greek children. Poster presentation at the COST Action A33 final conference Let the Children Speak. Wellcome Collection, London, January 22-24.

Ibrahim, R., Eviatar, Z., Aharon Peretz, J. 2007. Metalinguistic awareness and reading performance. Journal of Psycholinguist Research 36(4), 297-317.

Papapavlou, A., Pavlou P. 1998. A review of the sociolinguistic aspects of the Greek Cypriot dialect. Journal of Multilingual and Multicultural Development 19, 212220.

Petinou, K., Terzi A. 2002. Clitic misplacement among normally developing children and children with specific language impairment and the status of Infl heads. Language Acquisition 10, 1-28.

Varlokosta, S. et al. [= a large number of participants from COST Action A33: WG1]. To appear. A cross-linguistic study of the acquisition of pronoun and clitic production. Language Acquisition. 